\title{
Stem cell technology for bone regeneration: current status and potential applications
}

This article was published in the following Dove Press journal:

Stem Cells and Cloning:Advances and Applications

10 February 2015

Number of times this article has been viewed

\section{Greg Asatrian' \\ Dalton Pham ${ }^{1,2}$ \\ Winters R Hardy ${ }^{3}$ \\ Aaron W James ${ }^{1-3}$ \\ Bruno Peault $t^{3,4}$}

'Dental and Craniofacial Research Institute and Section of Orthodontics, School of Dentistry, ${ }^{2}$ Department of Pathology and Laboratory Medicine, David Geffen School of Medicine, ${ }^{3}$ UCLA/Orthopaedic Hospital Department of Orthopaedic Surgery and the Orthopaedic Hospital Research Center, Los Angeles, CA, USA; ${ }^{4}$ Medical Research Council Centre for Regenerative Medicine, Edinburgh, Scotland, UK
Correspondence: Bruno Peault 615 Charles EYoung Drive South, Los Angeles, CA 90095-7358, USA

$\mathrm{Tel}+$ I 310794 I339

Fax + I 3108255409

Email bpeault@mednet.ucla.edu
Abstract: Continued improvements in the understanding and application of mesenchymal stem cells (MSC) have revolutionized tissue engineering. This is particularly true within the field of skeletal regenerative medicine. However, much remains unknown regarding the native origins of MSC, the relative advantages of different MSC populations for bone regeneration, and even the biologic safety of such unpurified, grossly characterized cells. This review will first summarize the initial discovery of MSC, as well as the current and future applications of MSC in bone tissue engineering. Next, the relative advantages and disadvantages of MSC isolated from distinct tissue origins are debated, including the MSC from adipose, bone marrow, and dental pulp, among others. The perivascular origin of MSC is next discussed. Finally, we briefly comment on pluripotent stem cell populations and their possible application in bone tissue engineering. While continually expanding, the field of MSC-based bone tissue engineering and regeneration shows potential to become a clinical reality in the not-so-distant future.

Keywords: mesenchymal stem cell, pericyte, bone tissue engineering, MSC, ASC, DMSC

\section{Introduction}

Continued improvements in the understanding and application of adult mesenchymal stem cells (MSC) have revolutionized tissue engineering, particularly within the field of skeletal regenerative medicine. Although still in their relative infancy, multiple stem cell-based products have been used tentatively in humans for bone ${ }^{1}$ and cartilage ${ }^{2}$ regeneration. Furthermore, the delivery modality upon which these stem cell-based products are implanted is currently being investigated. To optimize bone healing, investigators must select a scaffold capable of maintaining, inducing, and restoring biological function. Scaffolds must be evaluated for their ability to not only maintain MSC survival, but also to promote MSC proliferation and differentiation. Moreover, such a scaffold must have appropriate degradation and nonimmunogeneic properties. ${ }^{3}$ The currently studied in vivo scaffolds differ widely, encompassing organic autogenic, allogeneic, and demineralized bone matrix grafts, as well as synthetic polymers, bioactive ceramics, cross-linked hydrophilic hydrogels, metals, and composite scaffolds, which range from osteoinductive to relatively inert. ${ }^{4,5}$

The widespread clinical use of MSC, although not a present reality, is conversely not a distant possibility. This review will first summarize the discovery of MSC, their applications in bone tissue engineering, and drawbacks of various MSC populations. The perivascular origin of MSC will then be discussed. Subsequently, we will briefly discuss pluripotent stem cell populations and their possible application in bone tissue engineering, including embryonic and induced pluripotent stem cells. Nonetheless, 
despite the great progress made since the discovery and characterization of MSC, certain key areas of MSC identity, safety, and efficacy must be addressed before the clinical translation of MSC-based bone tissue engineering becomes a reality.

\section{MSC defined}

MSC are in vitro cultured cells capable of multilineage mesenchymal differentiation and self-renewal. ${ }^{6,7}$ In 2006, the Mesenchymal and Tissue Stem Cell Committee of the International Society for Cellular Therapy published the four minimal criteria that classify a cell as a MSC. ${ }^{8}$ First, MSC are plastic-adherent when kept in standard culture conditions. Second, they must be multipotent stromal cells that can differentiate into osteoblasts, chondrocytes, and adipocytes. Third, they express the biomarkers CD73, CD90, and CD105. Finally, they must not express CD14, CD11b, CD34, CD45, CD19, and CD79 alpha. ${ }^{8}$

It is interesting to note that differentiation down neurogenic or myogenic lineages is not necessarily required for MSC, as put forth by the Mesenchymal and Tissue Stem Cell Committee. ${ }^{8}$ This qualification is consistent with the observed heterogeneity of the MSC populations isolated from different donors that contain subsets of cells that differ in terms of cell surface marker expression and transcriptional profiles, multidifferentiation potential, and clonogenicity. ${ }^{9-11}$ Moreover, others have protested this definition, stating that the unequivocal immunophenotyping hampers studies in other animal models due to the lack of a single specific marker and the limited availability of monoclonal antibodies. ${ }^{12}$ Due to these issues, no unifying criteria have been uniformly embraced.

Despite the parameters set forth for the retrospective identification of MSC in culture, the in situ identity of MSC has long been elusive. ${ }^{13}$ After the initial discovery of MSC in bone marrow, numerous other sources of MSC were identified, including tissues of fetal origin (umbilical cord, umbilical cord blood, or placenta), as well as diverse adult tissues (dermis, dental pulp, periosteum, blood vessels, synovial membrane, endometrium, and adipose tissue, among others) (Figure 1). ${ }^{14-19}$ In fact, nearly every tissue type and organ has been cited as housing MSC-type cells, leading some to hypothesize that blood vessels themselves are the in situ origin for the MSC progenitor cells ${ }^{20}$ (see the "Perivascular stem cells [PSC]" section). Although MSC-type cells have been identified and isolated from various tissue sources using the same criteria, differences in therapeutic efficacy exist, which we will discuss in context with their tissue of origin.

\section{Bone marrow stromal cells (BMSC)}

As demonstrated in a series of experiments performed in the mid-1960s, reviewed by Friedenstein et al, BMSC could be co-isolated in vitro alongside hematopoietic cells. ${ }^{21}$ BMSC are classified as MSC; however, one must note that bone marrow consists of many stromal cells, which are not - and do not - give rise to MSC. Nonetheless, the purified BMSC are considered MSC as they abide by the 2006 criteria and exhibit both plasticity and the ability to

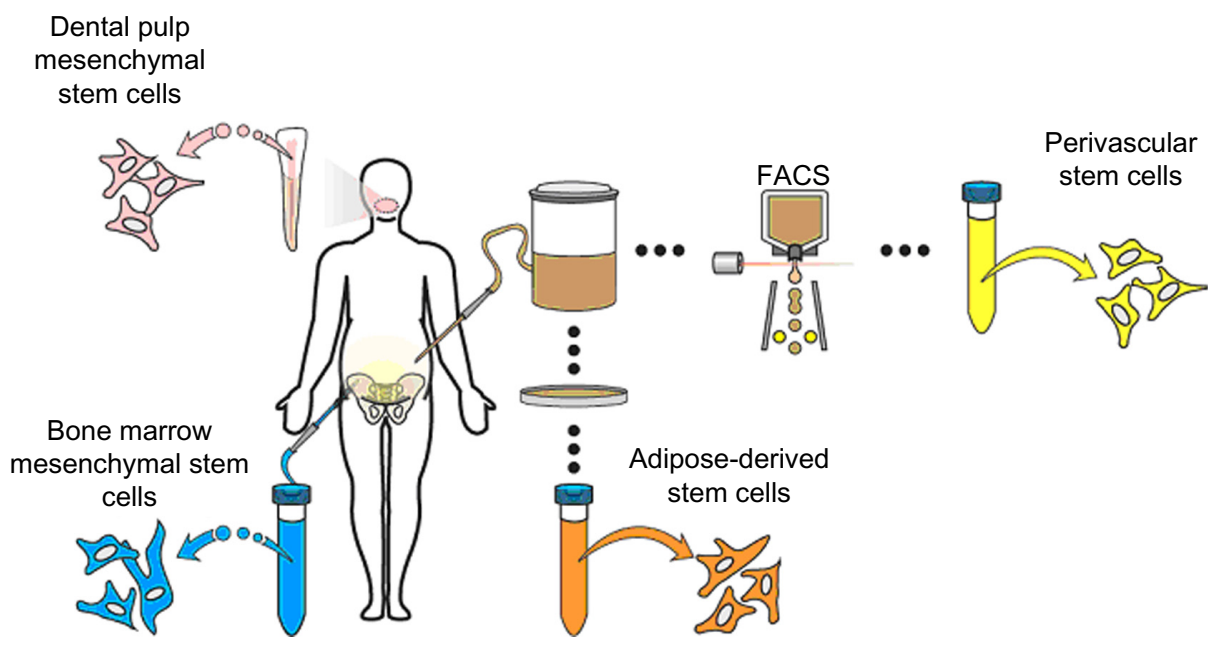

Figure I Representative sites of MSC isolation.

Notes: MSC can be isolated from diverse anatomic sites, some of which are depicted here. The most well-studied site of derivation is bone marrow, followed by adipose tissue, dental pulp, and others. MSC are designated by their site of derivation as, for example, BMSC, ASC, and DMSC. Alternatively, purified MSC populations have been named based on their PSC. Although most commonly derived from adipose tissue, PSC may be obtained from diverse human organs using FACS technology.

Abbreviations: DMSC, dental pulp mesenchymal stem cells; FACS, fluorescence-activated cell sorting; PSC, perivascular stem cells; BMSC, bone marrow mesenchymal stem cells; ASC, adipose-derived stem cells; MSC, mesenchymal stem cell. 
differentiate into chondrocytes, osteocytes, and adipocytes in vitro and in vivo. ${ }^{22,23}$ In 1997, Komori et al discovered that some marrow stromal cells express the master osteogenic transcription factor, runt-related transcription factor 2 (Runx2). ${ }^{24}$ Interestingly, regardless of differentiation, the BMSC retain Runx2 expression, suggesting an ability to shift phenotype and redifferentiate into osteoblasts..$^{25,26}$

Since their discovery, the BMSC have been extensively studied from a preclinical perspective to investigate their role and osteogenic potential. BMSC in vivo studies have used a wide array of both organic materials (eg, bovine cancellous bone $^{27}$ and allogeneic bone grafts ${ }^{28-30}$ ) and inorganic materials (eg, macroporous calcium phosphate cement, ${ }^{31}$ collagen sponge, ${ }^{32}$ polylactic acid, ${ }^{33}$ hydroxyapatite [HA], ${ }^{28,34} \mathrm{HA} /$ tricalcium phosphate $[\mathrm{TCP}],{ }^{34,35}$ and $\left.\beta-\mathrm{TCP}^{36}\right)$, among others. Numerous small animal studies have revealed the ability for BMSC to induce the healing of critical-sized craniomaxillofacial defects in a murine model, ${ }^{27,31}$ repair critical-sized femoral defects in rats ${ }^{32}$ and rabbits, ${ }^{33}$ and induce spinal fusion in rabbits. ${ }^{28}$

Moreover, several investigators have also shown the efficacy of local implantation of BMSC in various large animal models, including maxillofacial regeneration, ${ }^{37}$ spinal fusion, ${ }^{27,32}$ and in the healing of the critical-sized appendicular defects in dogs. ${ }^{32,35}$ Similar studies have been performed in sheep and have demonstrated the efficacy of BMSC to promote posterolateral spinal fusion, ${ }^{34}$ as well as repair long bone defects. ${ }^{29,30}$ In 2008, Gan et $\mathrm{al}^{36}$ translated these preclinical findings into a clinical setting and demonstrated the efficacy of BMSC to induce posterolateral spinal fusion in humans. Thus, BMSC have shown immense potential in multiple small and large animal studies and in a wide range of medical applications involving fracture and bone reconstruction.

In a clinical setting, however, the therapeutic use of MSC is hindered by several drawbacks that include the low yield of BMSC procurement, the use of growth factors and extensive in vitro culture for their expansion to therapeutically useful levels, and the inherent heterogeneity they display in their multidifferentiation potential. Because of the extremely low yields of BMSC progenitors (typically $0.001 \%-0.01 \%$ ) obtained from bone marrow aspirates, large quantities of bone marrow must be procured, which can cause additional donor site morbidity. ${ }^{38}$

Moreover, BMSC require several passages in culture to purify the original heterogeneous population comprised of hematopoietic and other cell types. ${ }^{39}$ When poorly purified from phenotypically different cells, BMSC possess variable morphology, a limited capacity for self-renewal, and are less efficiently differentiated. ${ }^{40,41}$ Last, the conditions and duration of culture can also alter their differentiation potential, as can the growth factors that are often used to promote the proliferation of BMSC. ${ }^{42-44}$ These significant limitations have hindered the translation of BMSC into a clinical setting, leading investigators to seek alternative tissue sources from which to isolate MSC.

Even with seemingly pure preparations of BMSC, only a percentage of BMSC in the population are susceptible to osteogenesis. ${ }^{45}$ In clonal studies characterizing adipogenic, osteogenic, and chondrogenic potentials, three categories comprised of four subgroups were shown to account for $\sim 90 \%$ of all colony-forming MSC in healthy donors: tripotent; bipotent (both osteoadipogenic and osteochondrogenic); and unipotent (osteogenic) colonies. ${ }^{11}$ Tripotent cells, which constituted $\sim 50 \%$ of the clones in this study, were highly proliferative, possessed large colony-forming efficiencies (35\%-90\%), and accumulated a more highly mineralized extracellular matrix than did cells from unipotent osteogenic clones, which formed colonies $5 \%$ or less of the time. ${ }^{46}$ Other research groups have enumerated this tripotent fraction of BMSC-derived clones at between 7\%-13.3\%, and in the latter case, have exhibited an associated expression of the surface marker CD271 (the low-affinity nerve growth factor receptor, a p75 neurotrophin receptor) with tripotent clones. ${ }^{47,48}$ Although specific estimates as to the number of tripotent cells BMSC vary, it is obvious that unfractioned BMSC expanded in culture exhibit variable functional efficacy.

\section{Adipose-derived stem cells (ASC)}

An alternative site for MSC isolation is adipose tissue. ASC, initially termed processed lipoaspirate, were first discovered in 2001 by Zuk et $\mathrm{a}^{49}$ and have been extensively evaluated for tissue engineering - in particular, for bone formation. Abundant in supply and readily and safely accessible, subcutaneous fat obtained via routine liposuction can be digested with collagenase immediately postisolation to produce a mixed-cell homogenate termed the stromal vascular fraction (SVF), which contains ASC in addition to endothelial, hematopoietic, and stromal cells. ${ }^{50,51}$ Although SVF has been studied in the confines of bone biology, the cells yield poor bone formation upon implantation, presumably due to the presence of mixed stromal and endothelial cells that both dilute and interact with the ASC present in the SVF. ${ }^{52}$ Fortunately, MSC may be produced by culturing the SVFs that are more homogenous for expression of the cell markers CD73, CD90, CD44, and CD9. ${ }^{53}$ Following flow cytometry characterization, it was determined that adipose stem cells 
also express the progenitor cell marker CD34 and secrete vascular endothelial growth factor, in addition to many other trophic factors. ${ }^{50,51,54}$ Upon allocation for culture, ASC have been shown to possess trilineage potential and to undergo osteogenic differentiation when treated with ascorbic acid, bone morphogenetic protein-2, and $\beta$-glycerophosphate. ${ }^{55}$

Like BMSC, population heterogeneity is also exhibited by ASC (selected by adherence to plastic). In aggregate, ASC represent a significant stem cell population, as they are abundant in supply and can be easily procured and isolated. However, at the clonal level, only $21 \%$ of the population of plastic-adherent ASC clones was determined to be tripotent, with an additional $31 \%$ and $29 \%$ possessing bipotent and unipotent behavior, respectively. ${ }^{56}$ Interestingly, only $48 \%$ of the clones were osteogenic, which suggests that the surface marker prognostic for osteogenic potency would improve the efficacy and consistency of these cells for bone tissue engineering.

The immense osteogenic potential of ASC has been demonstrated in numerous preclinical animal studies. In small animal models, ASC have been demonstrated to repair critical-sized calvarial defects, ${ }^{57,58}$ to promote bone formation in appendicular defects, ${ }^{59-61}$ and to induce spinal fusion in murine models. ${ }^{62}$ Similarly, in a large animal canine model, implanted ASC were observed to promote bone formation for craniomaxillofacial repair. ${ }^{63} \mathrm{~A}$ wide variety of scaffolds have been used in ASC-mediated bone repair, such as organic apatite-coated poly(lactic-co-glycolic) acid scaffolds, ${ }^{57,58}$ collagen-ceramic carriers, ${ }^{60}$ type I collagen matrix, ${ }^{62}$ and coral scaffolds, ${ }^{63}$ among others. Thus, ASC have been validated to possess significant efficacy and consistent osteogenic potential, as witnessed in various small and large animal models.

Although robust quantities of bone are induced when ASC are implanted in vivo, the SVF must be passaged several times in culture to reduce ASC contamination by other cell types present in the SVF, which precludes their use at the point of care. Furthermore, the in vitro cultivation has been shown to decrease stemness, self-renewal, and multipotency ${ }^{64}$ and, in some cases, has resulted in genomic instability - a potential concern for spontaneous malignant transformation. ${ }^{65}$ The proliferative capacity of ASC is also inversely correlated with patient age - a significant drawback for applications involving geriatric and osteoporotic patients. ${ }^{66}$

Although also observed in other MSC populations, the ASC have been reported to release trophic factors, such as angiopoietin-like 1, EGF, FGF, HGF, TGF $\beta$, and CXCL12, as well as the immunosuppressive cytokines prostaglandin
E2 (PGE2) and indoleamine 2,3-dioxygenase (IDO). ${ }^{67-70}$ While growth and stem cell recruitment factors stimulate tissue regeneration, the immunosuppressive properties of these cells suggest that either allogeneic or autologous ASC can be successfully used in tissue repair without triggering a lymphocyte reaction. ${ }^{71}$ Further work, however, must be done to investigate whether an immune reaction may be triggered when ASC differentiate. This dual mitogenic/immunomodulatory potential of ASC, however, may have a dark side, as it may stimulate cancer cell proliferation, while at the same time diminish T-cell proliferation, which could have taken part in a cytotoxic, antineoplastic response. ${ }^{72-79}$ Furthermore, mechanisms, such as the ASC-mediated secretion of CXCL12 and FGFR2, have been shown to increase tumor cell migration and angiogenesis, respectively. ${ }^{66,80}$ Thus, ASC may not be the best choice for bone reconstruction after tumor resection. Overall, while ASC have significant advantages in their relative abundance and bone-forming potential, culture requirement and trophic factor elaboration remain safety concerns for their future use.

\section{Perivascular stem cells (PSC)}

As MSC are consistently isolated from tissues rich in vasculature, such as bone marrow and adipose tissue, we and other investigators have recently sought to determine whether MSC ancestors are natively associated with blood vessels. In 2008, the pericytes, which line capillaries and microvasculature, were discovered to possess multipotent differentiation potential. ${ }^{51,81}$ This led Professor Arnold Caplan of Case Western Reserve University to speculate and propose that all MSC are, in fact, derived from pericytes. ${ }^{20}$ In 2012 , Corselli et $\mathrm{al}^{82}$ reported that in addition to MSC being derived from pericytes, adventitial cells could also give rise to MSC. Adventitial cells are a population of CD34+, multipotent cells that are antigenically distinct to pericytes and are observed to mobilize in response to trauma and hypoxia. ${ }^{82-85}$ In a recent article by Zhao et al, ${ }^{86}$ it was demonstrated that during incisor trauma, periarterial cells (pericytes and adventitial cells) are recruited to modulate hemostasis and repair. Further, in vitro, these cells were shown to exhibit typical MSC characteristics. ${ }^{86}$ Thus, when taken together, pericytes (CD31-/CD45-/CD34-/CD146+), found encompassing microvessels and capillaries, and adventitial cells (CD31-/ CD45-/CD34+/CD146-), localized in the outmost layer of larger arteries and veins, compose PSC. ${ }^{87}$

As adipose is a highly vascularized tissue and is ample in supply, most PSC safety and efficacy studies have isolated PSC from routine liposuction procedures. Unlike 
plastic-selected ASC, which require weeks of culture, pericytes (CD45-/CD146-/CD34+) and adventitial cells (CD45-/CD146+/CD34-) are purified via fluorescent-activated cell sorting (FACS) in a process that requires merely a few hours (Figure 2). ${ }^{87,88}$ Moreover, the PSC obtained from fat are superior to BMSC and dental pulp mesenchymal stem cells (DMSC), as they can be procured in abundance with minimal patient morbidity. Further, as the PSC are purified via FACS instead of being cultured, and since they are autologous, the minimal risk of in vitro transformation and immunogeneic rejection exists. Thus, PSC are a novel and promising stem cell population shown to possess trilineage potential and are superior to the aforementioned stem cell populations, as they can be isolated in large quantities and can be purified in a relatively short time.

Since their discovery, PSC have been studied in various preclinical models to investigate their osteogenic potential. PSC have been delivered on demineralized bone matrix ${ }^{89-91}$ or via HA-coated poly(lactic-co-glycolic) acid. ${ }^{92}$ Human PSC significantly improved healing in a mouse criticalsize calvarial defect model when compared to human SVF (ie, SVF or unpurified lipoaspirates). ${ }^{92}$ Moreover, the PSC also induced robust bone formation following implantation in a murine muscle pouch model and femoral segmental defect model. ${ }^{91}$ In a recent study, PSC implantation induced successful lumbar spinal fusion in rats, with markedly increased bone formation. ${ }^{89}$ Samples implanted with PSC expressed increased bone stiffness and capacity to withstand force via finite elemental analysis - a nondestructive biomechanical assay. ${ }^{90}$ Thus, PSC combine two separately studied perivascular stem cell populations that can be readily isolated to homogeneity from lipoaspirates via FACS, whose capability has been validated in the induction of robust osteogenesis.

\section{Dental pulp mesenchymal stem cells}

MSC have also been purified from human exfoliated deciduous teeth, and termed DMSC. ${ }^{93}$ In 2003, Shi and Gronthos ${ }^{94}$ successfully utilized the antibody STRO-1 to probe and isolate dental pulp stem cells through immunoselection. Through immunohistochemistry, FACS, and immunomagnetic bead selection, Shi and Gronthos ${ }^{94}$ determined that dental pulp stem cells express the pericyte markers CD146 and 3G5. This interesting observation brings up the question as to the overlapping identity of DMSC and PSC.

The preclinical studies of DMSC have shown some promise in bone biology. Several small animal studies have demonstrated the potential of DMSC in the regeneration of critical-sized calvarial defects in mice. ${ }^{95,96}$ For instance, MSC derived from the periodontal ligament and gingival tissue possess the ability to repair critical-size calvarial defects in mice by promoting the formation of mineralized tissue on arginine-glycine-aspartic acid tripeptide-modified alginate scaffolds, as well as on gelatin sponge scaffolds. ${ }^{95,96}$ In canine and swine models, the local implantation of DMSC with $\beta$-TCP and HA/TCP scaffolds has been shown to induce successful bone regeneration in critical-sized orofacial bone defects. ${ }^{97,98}$ Although less efficacious than BMSC, the DMSC were able to regenerate alveolar bone at 8 weeks postimplantation in a canine model. ${ }^{98}$ In fact, DMSC have also been shown to repair alveolar ridge and mandibular defects in humans, utilizing collagen sponge scaffolds. ${ }^{99,100}$

While dental pulp might pose as an alternative site for MSC isolation, the use of DMSC is limited by the small

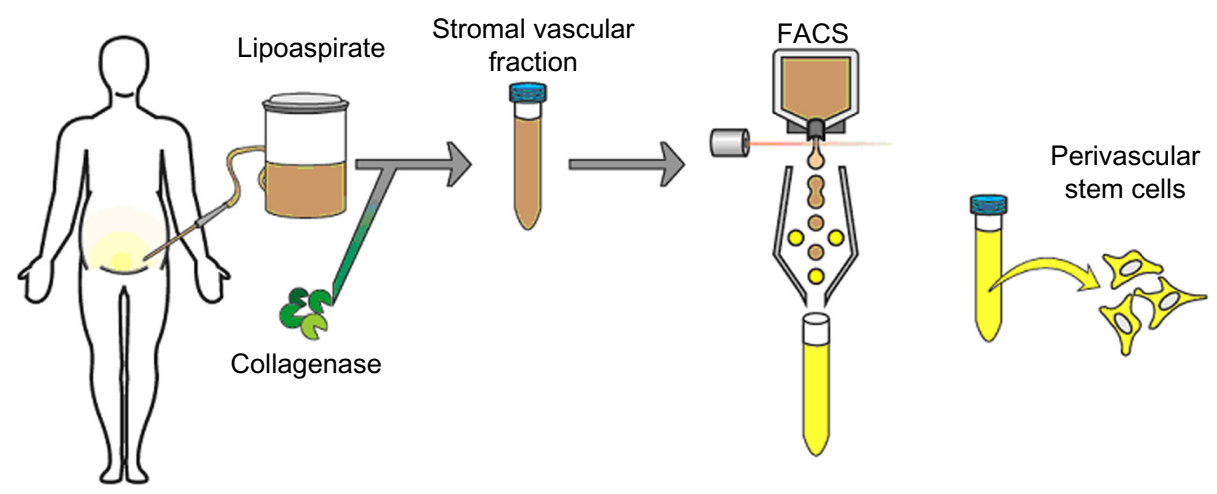

Figure 2 Purification process for PSC.

Notes: Although typically isolated from human lipoaspirate, PSC can be extracted from any vascularized organ. After routine liposuction or lipectomy, adipose tissue undergoes enzymatic digestion with collagenase to yield the SVF of adipose tissue. SVF is then purified for PSC via FACS for the differential expression of perivascular markers. As is currently understood, PSC are a bipartite population including CDI46+ pericytes and CD34+ adventitial cells.

Abbreviations: FACS, fluorescence-activated cell sorting; PSC, perivascular stem cells; SVF, stromal vascular fraction. 
quantity of pulp in a tooth, the proportionally smaller DMSC yield that necessitates their expansion by long-term culture, and the corresponding costs and risks that are incurred. Aside from the pragmatic concerns, several investigators have also reported the limited potential of DMSC to regenerate bone in vivo. ${ }^{101-105}$ For instance, while DMSC were observed to promote bone formation in a human mandibular defect, the de novo bone formed was primarily composed of cortical bone, lacking vasculature. ${ }^{100}$ Moreover, in a manuscript by Annibali et al, ${ }^{101}$ DMSC did not significantly induce more bone than did controls in a critical-sized calvarial defect in mice. This observation may be a consequence of the fact that as DMSC undergo high-passage propagation, fewer and fewer stem cells are present. ${ }^{106}$ So, despite the fact that DMSC show some utility for bone regeneration, they do not supplant therapies enlisting BMSC or PSC.

\section{Embryonic stem cells (ESC)}

Several investigators have also explored the regenerative potential of ESC for applications involving bone. The ESC are a pluripotent stem cell population which, by definition, possess an unlimited potential to differentiate into all three germ tissue lineages: ectoderm; endoderm; and mesoderm. An unlimited capacity for self-renewal is highly valuable for continued research and affords ESC a considerable advantage for regenerative medicine and the consistent manufacture of an allogeneic product for bone repair. In this context, ESC have been studied in various preclinical assays to investigate their innate osteogenic potential as well as their influence in coculture with other stem cells in the presence of growth factors. Alone, ESC have been observed to possess robust osteogenic potential and are capable of osteogenic differentiation with or without the stage-specific changes that occur in the normal development of the embryoid body. ${ }^{107}$ When cocultured with human BMSC that had undergone osteogenesis, the bone nodules formed from human ESC (hESC) were more mineralized and were richer in osteocalcin, an extracellular bone matrix protein. These findings suggest that paracrine factors secreted from differentiated human BMSC (hBMSC) promote osteogenic differentiation in hESC. ${ }^{108}$ Independently, when ESC are treated with numerous growth factors, a synergistic effect is observed where osteogenic differentiation of hESC is enhanced compared to using a single growth factor. ${ }^{109}$

From these studies, it appears that the extracellular matrix plays a crucial role in contributing to osteogenic lineage specification during embryonic development; ${ }^{110-112}$ thus, in order to successfully optimize ESC for bone regeneration, scaffolds must be implemented that mimic the natural extracellular matrix of bone tissue and act as a directive template for the osteogenic specification of ESC. ${ }^{113}$

Major obstacles exist, however, in realizing the translational potential of ESC, including allogeneic rejection and teratoma formation. Previous investigators have witnessed allogeneic rejection upon implantation, with marked rejection of donor cells possessing foreign human leukocyte antigens. ${ }^{114}$ In a recent study by Aldahmash et al, ${ }^{115}$ it was observed that the implantation of undifferentiated ESC induced teratoma formation, a tumor comprised of all three cell lineages. As such, the punctilious removal of any undifferentiated cell is imperative prior to administration. Although efficacy studies have shown promise in the osteogenic potential of ESC, safety issues limit the potential clinical use of ESC for bone tissue engineering.

\section{Induced pluripotent stem cells (iPSC)}

In 2006, the iPSC were created in Shinya Yamanaka's laboratory at Kyoto University from mouse fibroblasts by the retroviral ectopic transduction of the genes Oct4, Sox2, Klf4, and $c-M y c .{ }^{116}$ Although most commonly derived from primary dermal fibroblasts, iPSC can be created from many different adult cell lineages via their cellular reprogramming to a pluripotent state. ${ }^{117-119}$ Because iPSC possess a pluripotent potential similar to that of ESC, but they are derived from the cells of the adult patient undergoing treatment, they do not generate an allograft immune response. ${ }^{120}$

In a preclinical setting, iPSC have been observed to promote robust bone regeneration both in vitro and in vivo. In fact, in a 2010 study by Kao et al, ${ }^{121}$ the iPSC were observed to possess comparable osteogenic potential to that of ESC. Implantation studies have demonstrated the potential of iPSC to promote bone formation in a mouse knee defect as well as in the murine ectopic subcutaneous injection models, utilizing collagen hydrogen scaffolds and macrochanneled poly(caprolactone) scaffolds. ${ }^{122,123}$ Furthermore, in 2012, Levi et al ${ }^{124}$ demonstrated complete healing of critical-sized calvarial defects in mice implanted with human iPSC. Unfortunately, like ESC, the iPSC that have not been thoroughly differentiated prior to implantation can undergo teratoma formation. ${ }^{16,125}$ Although the frequency of teratoma formation with iPSC is not as prevalent as with ESC, the presence of teratomas, again, shows the instability of pluripotent stem cell application in bone and tissue engineering.

Another major drawback of iPSC is their poor yield of induction; $<1 \%$ success was observed in the induction of iPSC from murine adult somatic cells. As such, clinical 
translation is rendered difficult due to the necessity of starting with large quantities of tissue. ${ }^{126,127}$

\section{Conclusion}

In conclusion, although several MSC populations hold great promise in bone-forming potential, the clinical application will require that the identity, safety, and efficacy of these cells be well validated. ${ }^{128}$ Currently, the very native identity of MSC is ensconced in some mystery and remains a controversial subject with different investigators isolating MSC via differing techniques (eg, selection by culture versus immunophenotype) or establishing MSC identity by different parameters. In addition, the perivascular/pericytic origin of MSC is becoming an increasingly well-accepted theory, although complete agreement as to the origin, function, and clinical potential of these cells is lacking, as are the changes that these cells undergo during isolation, cultivation, and reintroduction to the host. In terms of safety, tumor formation and malignant transformation of MSC remain a possible risk, ${ }^{129}$ although most studies suggest that this is a theoretical rather than a tangible risk. On the other hand, ESC and iPSC, while capable of bone formation, possess tumorigenic potential by forming teratomas. Finally, in terms of efficacy, the question remains as to whether different MSC depots or subpopulations are more osteogenic than others. Comparisons have been made across MSC obtained from donors of different ages and sexes, and from different anatomic locations and tissues, using different cell surface markers for identification. Yet, an unequivocal cell source (or the gold standard) for MSC-based bone tissue engineering and regeneration has not yet been defined. By utilizing a prospectively purified, noncultured population of stem cells, such as PSC, future studies can alleviate the number of drawbacks associated with the utilization of long-term cultured convention MSC. Thus, despite the great progress made since the discovery and characterization of MSC, certain key areas of MSC identity, safety, and efficacy must be addressed before the clinical translation of MSC-based bone tissue engineering becomes a reality.

\section{Disclosure}

The authors report no conflicts of interest in this work.

\section{References}

1. Knight MN, Hankenson KD. Mesenchymal stem cells in bone regeneration. Adv Wound Care (New Rochelle). 2013;2(6):306-316.

2. Deng S, Huang R, Wang J, et al. Miscellaneous animal models accelerate the application of mesenchymal stem cells for cartilage regeneration. Curr Stem Cell Res Ther. 2014;9(3):223-233.
3. Billström GH, Blom AW, Larsson S, Beswick AD. Application of scaffolds for bone regeneration strategies: current trends and future directions. Injury. 2013;44 Suppl 1:S28-S33.

4. Yarlagadda PK, Chandrasekharan M, Shyan JY. Recent advances and current developments in tissue scaffolding. Biomed Mater Eng. 2005;15(3):159-177.

5. Tevlin R, McArdle A, Atashroo D, et al. Biomaterials for Craniofacial Bone Engineering. J Dent Res. 2014.

6. Oswald J, Boxberger S, Jørgensen B, et al. Mesenchymal stem cells can be differentiated into endothelial cells in vitro. Stem Cells. 2004;22(3):377-384.

7. Bianco P, Robey PG, Simmons PJ. Mesenchymal stem cells: revisiting history, concepts, and assays. Cell Stem Cell. 2008;2(4):313-319.

8. Dominici M, Le Blanc K, Mueller I, et al. Minimal criteria for defining multipotent mesenchymal stromal cells. The International Society for Cellular Therapy position statement. Cytotherapy. 2006;8(4): 315-317.

9. Mosna F, Sensebé L, Krampera M. Human bone marrow and adipose tissue mesenchymal stem cells: a user's guide. Stem Cells Dev. 2010;19(10):1449-1470.

10. Wagner W, Feldmann RE Jr, Seckinger A, et al. The heterogeneity of human mesenchymal stem cell preparations - evidence from simultaneous analysis of proteomes and transcriptomes. Exp Hematol. 2006;34(4):536-548.

11. Russell KC, Phinney DG, Lacey MR, Barrilleaux BL, Meyertholen KE, O'Connor KC. In vitro high-capacity assay to quantify the clonal heterogeneity in trilineage potential of mesenchymal stem cells reveals a complex hierarchy of lineage commitment. Stem Cells. 2010;28(4): 788-798.

12. De Schauwer C, Meyer E, Van de Walle GR, Van Soom A. Markers of stemness in equine mesenchymal stem cells: a plea for uniformity. Theriogenology. 2011;75(8):1431-1443.

13. da Silva Meirelles L, Caplan AI, Nardi NB. In search of the in vivo identity of mesenchymal stem cells. Stem Cells. 2008;26(9):2287-2299.

14. Pojda Z, Machaj E, Kurzyk A, et al. [Mesenchymal stem cells]. Postepy Biochemi. 2013;59(2):187-197. Polish.

15. Young HE, Steele TA, Bray RA, et al. Human reserve pluripotent mesenchymal stem cells are present in the connective tissues of skeletal muscle and dermis derived from fetal, adult, and geriatric donors. Anat Rec. 2001;264(1):51-62.

16. Nakahara H, Goldberg VM, Caplan AI. Culture-expanded human periosteal-derived cells exhibit osteochondral potential in vivo. J Orthop Res. 1991;9(4):465-476.

17. Diefenderfer DL, Brighton CT. Microvascular pericytes express aggrecan message which is regulated by BMP-2. Biochem Biophys Res Commun. 2000;269(1):172-178.

18. De Bari C, Dell'Accio F, Luyten FP. Human periosteum-derived cells maintain phenotypic stability and chondrogenic potential throughout expansion regardless of donor age. Arthritis Rheum. 2001;44(1):85-95.

19. Spitzer TL, Rojas A, Zelenko Z, et al. Perivascular human endometrial mesenchymal stem cells express pathways relevant to self-renewal, lineage specification, and functional phenotype. Biol Reprod. 2012;86(2):58.

20. Caplan AI. All MSCs are pericytes? Cell Stem Cell. 2008;3(3):229-230.

21. Friedenstein AJ. Osteogenic stem cells in bone marrow. In: Heersche JNM, Kanis JA, editors. Bone and Mineral Research. Amsterdam: Elsevier;1990:243-272.

22. Bennett JH, Joyner CJ, Triffitt JT, Owen ME. Adipocytic cells cultured from marrow have osteogenic potential. J Cell Sci. 1991; 99(Pt 1):131-139.

23. Beresford JN, Bennett JH, Devlin C, Leboy PS, Owen ME. Evidence for an inverse relationship between the differentiation of adipocytic and osteogenic cells in rat marrow stromal cell cultures. J Cell Sci. 1992;102(Pt 2):341-351.

24. Komori T, Yagi H, Nomura S, et al. Targeted disruption of Cbfa1 results in a complete lack of bone formation owing to maturational arrest of osteoblasts. Cell. 1997;89(5):755-764. 
25. Galotto M, Campanile G, Robino G, Cancedda FD, Bianco P, Cancedda R. Hypertrophic chondrocytes undergo further differentiation to osteoblast-like cells and participate in the initial bone formation in developing chick embryo. J Bone Miner Res. 1994;9(8):1239-1249.

26. Gentili C, Bianco P, Neri M, et al. Cell proliferation, extracellular matrix mineralization, and ovotransferrin transient expression during in vitro differentiation of chick hypertrophic chondrocytes into osteoblast-like cells. J Cell Biol. 1993;122(3):703-712.

27. Zhao J, Yang C, Su C, et al. Reconstruction of orbital defects by implantation of antigen-free bovine cancellous bone scaffold combined with bone marrow mesenchymal stem cells in rats. Graefes Arch Clin Exp Ophthalmol. 2013;251(5):1325-1333.

28. Minamide A, Yoshida M, Kawakami M, et al. The use of cultured bone marrow cells in type I collagen gel and porous hydroxyapatite for posterolateral lumbar spine fusion. Spine (Phila Pa 1976). 2005;30(10): $1134-1138$.

29. Fernandes MB, Guimarães JA, Casado PL, et al. The effect of bone allografts combined with bone marrow stromal cells on the healing of segmental bone defects in a sheep model. BMC Vet Res. 2014;10:36.

30. Vélez R, Hernández-Fernández A, Caminal $\mathrm{M}$, et al. Treatment of femoral head osteonecrosis with advanced cell therapy in sheep. Arch Orthop Trauma Surg. 2012;132(11):1611-1618.

31. Chen W, Liu J, Manuchehrabadi N, Weir MD, Zhu Z, Xu HH. Umbilical cord and bone marrow mesenchymal stem cell seeding on macroporous calcium phosphate for bone regeneration in rat cranial defects. Biomaterials. 2013;34(38):9917-9925.

32. Rose T, Peng H, Shen HC, et al. The role of cell type in bone healing mediated by ex vivo gene therapy. Langenbecks Arch Surg. 2003; 388(5):347-355.

33. Yueyi C, Xiaoguang H, Jingying W, et al. Calvarial defect healing by recruitment of autogenous osteogenic stem cells using locally applied simvastatin. Biomaterials. 2013;34(37):9373-9380.

34. Shamsul BS, Tan KK, Chen HC, Aminuddin BS, Ruszymah BH. Posterolateral spinal fusion with ostegenesis induced BMSC seeded TCP/HA in a sheep model. Tissue Cell. 2014;46(2):152-158.

35. Arinzeh TL, Peter SJ, Archambault MP, et al. Allogeneic mesenchymal stem cells regenerate bone in a critical-sized canine segmental defect. J Bone Joint Surg Am. 2003;85-A(10):1927-1935.

36. Gan Y, Dai K, Zhang P, Tang T, Zhu Z, Lu J. The clinical use of enriched bone marrow stem cells combined with porous beta-tricalcium phosphate in posterior spinal fusion. Biomaterials. 2008;29(29): 3973-3982.

37. Liu X, Liao X, Luo E, Chen W, Bao C, Xu HH. Mesenchymal stem cells systemically injected into femoral marrow of dogs home to mandibular defects to enhance new bone formation. Tissue Eng Part A. 2014;20(3-4):883-892.

38. Bonab MM, Alimoghaddam K, Talebian F, Ghaffari SH, Ghavamzadeh A, Nikbin B. Aging of mesenchymal stem cell in vitro. BMC Cell Biol. 2006; 7:14.

39. Izadpanah R, Trygg C, Patel B, et al. Biologic properties of mesenchymal stem cells derived from bone marrow and adipose tissue. $J$ Cell Biochem. 2006;99(5):1285-1297.

40. Izadpanah $\mathrm{R}$, Kaushal $\mathrm{D}$, Kriedt $\mathrm{C}$, et al. Long-term in vitro expansion alters the biology of adult mesenchymal stem cells. Cancer Res. 2008;68(11):4229-4238.

41. Wagner W, Horn P, Castoldi M, et al. Replicative senescence of mesenchymal stem cells: a continuous and organized process. PLoS One. 2008;3(5):e2213.

42. Shoshani O, Zipori D. Mammalian cell dedifferentiation as a possible outcome of stress. Stem Cell Rev. 2011;7(3):488-493.

43. Bianchi G, Banfi A, Mastrogiacomo M, et al. Ex vivo enrichment of mesenchymal cell progenitors by fibroblast growth factor 2. Exp Cell Res. 2003;287(1):98-105.

44. Sotiropoulou PA, Perez SA, Salagianni M, Baxevanis CN, Papamichail M. Characterization of the optimal culture conditions for clinical scale production of human mesenchymal stem cells. Stem Cells. 2006;24(2):462-471.
45. Phinney DG. Functional heterogeneity of mesenchymal stem cells: implications for cell therapy. J Cell Biochem. 2012;113(9):2806-2812.

46. Russell KC, Lacey MR, Gilliam JK, Tucker HA, Phinney DG, O'Connor KC. Clonal analysis of the proliferation potential of human bone marrow mesenchymal stem cells as a function of potency. Biotechnol Bioeng. 2011;108(11):2716-2726.

47. Kuçi Z, Seiberth J, Latifi-Pupovci H, et al. Clonal analysis of multipotent stromal cells derived from CD271+ bone marrow mononuclear cells: functional heterogeneity and different mechanisms of allosuppression. Haematologica. 2013;98(10):1609-1616.

48. Lee CC, Christensen JE, Yoder MC, Tarantal AF. Clonal analysis and hierarchy of human bone marrow mesenchymal stem and progenitor cells. Exp Hematol. 2010;38(1):46-54.

49. Zuk PA, Zhu M, Mizuno H, et al. Multilineage cells from human adipose tissue: implications for cell-based therapies. Tissue Eng. 2001; 7(2):211-228.

50. Rehman J, Traktuev D, Li J, et al. Secretion of angiogenic and antiapoptotic factors by human adipose stromal cells. Circulation. 2004;109(10):1292-1298

51. Traktuev DO, Merfeld-Clauss S, Li J, et al. A population of multipotent CD34-positive adipose stromal cells share pericyte and mesenchymal surface markers, reside in a periendothelial location, and stabilize endothelial networks. Circ Res. 2008;102(1):77-85.

52. James AW, Zara JN, Zhang X, et al. Perivascular stem cells: a prospectively purified mesenchymal stem cell population for bone tissue engineering. Stem Cells Transl Med. 2012;1(6):510-519.

53. Hamid AA, Idrus RB, Saim AB, Sathappan S, Chua KH. Characterization of human adipose-derived stem cells and expression of chondrogenic genes during induction of cartilage differentiation. Clinics (Sao Paulo). 2012;67(2):99-106.

54. Caplan AI, Correa D. The MSC: an injury drugstore. Cell Stem Cell. 2011;9(1):11-15.

55. Schäffler A, Büchler C. Concise review: adipose tissue-derived stromal cells - basic and clinical implications for novel cell-based therapies. Stem Cells. 2007;25(4):818-827.

56. Guilak F, Lott KE, Awad HA, et al. Clonal analysis of the differentiation potential of human adipose-derived adult stem cells. J Cell Physiol. 2006;206(1):229-237.

57. Cowan CM, Shi YY, Aalami OO, et al. Adipose-derived adult stromal cells heal critical-size mouse calvarial defects. Nat Biotechnol. 2004;22(5):560-567.

58. Levi B, James AW, Nelson ER, et al. Human adipose derived stromal cells heal critical size mouse calvarial defects. PLoS One. 2010;5(6):e11177.

59. Abudusaimi A, Aihemaitijiang Y, Wang YH, Cui L, Maimaitiming S, Abulikemu M. Adipose-derived stem cells enhance bone regeneration in vascular necrosis of the femoral head in the rabbit. $J$ Int Med Res. 2011;39(5):1852-1860.

60. Peterson B, Zhang J, Iglesias R, et al. Healing of critically sized femoral defects, using genetically modified mesenchymal stem cells from human adipose tissue. Tissue Eng. 2005;11(1-2):120-129.

61. Sunay O, Can G, Cakir Z, et al. Autologous rabbit adipose tissue-derived mesenchymal stromal cells for the treatment of bone injuries with distraction osteogenesis. Cytotherapy. 2013;15(6):690-702.

62. Hsu WK, Wang JC, Liu NQ, et al. Stem cells from human fat as cellular delivery vehicles in an athymic rat posterolateral spine fusion model. J Bone Joint Surg Am. 2008;90(5):1043-1052.

63. Cui L, Liu B, Liu G, et al. Repair of cranial bone defects with adipose derived stem cells and coral scaffold in a canine model. Biomaterials. 2007;28(36):5477-5486.

64. Requicha JF, Viegas CA, Albuquerque CM, Azevedo JM, Reis RL, Gomes ME. Effect of anatomical origin and cell passage number on the stemness and osteogenic differentiation potential of canine adiposederived stem cells. Stem Cell Rev. 2012;8(4):1211-1222.

65. Bellotti C, Stanco D, Ragazzini S, et al. Analysis of the karyotype of expanded human adipose-derived stem cells for bone reconstruction of the maxillo-facial region. Int J Immunopathol Pharmacol. 2013;26(Suppl 1):3-9. 
66. Guercio A, Di Bella S, Casella S, Di Marco P, Russo C, Piccione G. Canine mesenchymal stem cells (MSCs): characterization in relation to donor age and adipose tissue-harvesting site. Cell Biol Int. 2013;37(8):789-798.

67. De Miguel MP, Fuentes-Julián S, Blázquez-Martínez A, et al. Immunosuppressive properties of mesenchymal stem cells: advances and applications. Curr Mol Med. 2012;12(5):574-591.

68. Lee SH, Jin SY, Song JS, Seo KK, Cho KH. Paracrine effects of adipose-derived stem cells on keratinocytes and dermal fibroblasts. Ann Dermatol. 2012;24(2):136-143.

69. Moon KM, Park YH, Lee JS, et al. The effect of secretory factors of adipose-derived stem cells on human keratinocytes. Int $J$ Mol Sci. 2012;13(1):1239-1257.

70. Nakao N, Nakayama T, Yahata T, et al. Adipose Tissue-Derived Mesenchymal Stem Cells Facilitate Hematopoiesis in Vitro and in Vivo. Am J Pathol. 2010;177(2):547-554.

71. Gimble JM, Grayson W, Guilak F, Lopez MJ, Vunjak-Novakovic G. Adipose tissue as a stem cell source for musculoskeletal regeneration. Front Biosci (Schol Ed). 2011;3:69-81.

72. Ostrand-Rosenberg S. Myeloid-derived suppressor cells: more mechanisms for inhibiting antitumor immunity. Cancer Immunol Immunother. 2010;59(10):1593-1600.

73. Carrade Holt DD, Wood JA, Granick JL, Walker NJ, Clark KC, Borjesson DL. Equine mesenchymal stem cells inhibit T cell proliferation through different mechanisms depending on tissue source. Stem Cells Dev. 2014;23(11):1258-1265.

74. Kim JH, Lee YT, Hong JM, Hwang YI. Suppression of in vitro murine T cell proliferation by human adipose tissue-derived mesenchymal stem cells is dependent mainly on cyclooxygenase-2 expression. Anat Cell Biol. 2013;46(4):262-271.

75. Mohammadzadeh A, Pourfathollah AA, Shahrokhi S, Hashemi SM, Moradi SL, Soleimani M. Immunomodulatory effects of adiposederived mesenchymal stem cells on the gene expression of major transcription factors of T cell subsets. Int Immunopharmacol. 2014;20(2): 316-321.

76. Djouad F, Plence P, Bony C, et al. Immunosuppressive effect of mesenchymal stem cells favors tumor growth in allogeneic animals. Blood. 2003;102(10):3837-3844.

77. Cuiffo BG, Karnoub AE. Mesenchymal stem cells in tumor development: emerging roles and concepts. Cell Adh Migr. 2012;6(3): 220-230

78. Karnoub AE, Dash AB, Vo AP, et al. Mesenchymal stem cells within tumour stroma promote breast cancer metastasis. Nature. 2007;449(7162):557-563.

79. Karnoub AE, Weinberg RA. Chemokine networks and breast cancer metastasis. Breast Dis. 2006;26:75-85.

80. Muehlberg FL, Song YH, Krohn A, et al. Tissue-resident stem cells promote breast cancer growth and metastasis. Carcinogenesis 2009;30(4):589-597.

81. Crisan M, Yap S, Casteilla L, et al. A perivascular origin for mesenchymal stem cells in multiple human organs. Cell Stem Cell. 2008;3(3):301-313.

82. Corselli M, Chen CW, Sun B, Yap S, Rubin JP, Péault B. The tunica adventitia of human arteries and veins as a source of mesenchymal stem cells. Stem Cells Dev. 2012;21(8):1299-1308.

83. Lin G, Garcia M, Ning H, et al. Defining stem and progenitor cells within adipose tissue. Stem Cells Dev. 2008;17(6):1053-1063.

84. Siow RC, Mallawaarachchi CM, Weissberg PL. Migration of adventitial myofibroblasts following vascular balloon injury: insights from in vivo gene transfer to rat carotid arteries. Cardiovasc Res. 2003;59(1):212-221.

85. Corselli M, Chen CW, Crisan M, Lazzari L, Péault B. Perivascular ancestors of adult multipotent stem cells. Arterioscler Thromb Vasc Biol. 2010;30(6):1104-1109.

86. Zhao H, Feng J, Seidel K, et al. Secretion of shh by a neurovascular bundle niche supports mesenchymal stem cell homeostasis in the adult mouse incisor. Cell Stem Cell. 2014;14(2):160-173.
87. Corselli M, Crisan M, Murray IR, et al. Identification of perivascular mesenchymal stromal/stem cells by flow cytometry. Cytometry $A$. 2013;83(8):714-720.

88. Askarinam A, James AW, Zara JN, et al. Human perivascular stem cells show enhanced osteogenesis and vasculogenesis with Nel-like molecule I protein. Tissue Eng Part A. 2013;19(11-12):1386-1397.

89. Asatrian GCC, James AW, Liang P, et al. Human Perivascular Mesenchymal Stem cells Promote Lumbar Spinal Fusion Via Induction of Osteogenesis and Vasculogenesis. Seattle, WA: International Association for Dental Research; 2013.

90. Chung CG KJ, Velasco O, Asatrian G, et al. Perivascular Stem Cells with NELL-1 Protein Induce Robust Spinal Fusion. Charlotte, NC: American Association of Dental Research; 2014.

91. James AW, Zara JN, Corselli M, et al. Use of human perivascular stem cells for bone regeneration. JVis Exp. 2012;(63):e2952.

92. James AW, Zara JN, Corselli M, et al. An abundant perivascular source of stem cells for bone tissue engineering. Stem Cells Transl Med. 2012;1(9):673-684.

93. Telles PD, Machado MA, Sakai VT, Nör JE. Pulp tissue from primary teeth: new source of stem cells. J Appl Oral Sci. 2011;19(3): 189-194.

94. Shi S, Gronthos S. Perivascular niche of postnatal mesenchymal stem cells in human bone marrow and dental pulp. J Bone Miner Res. 2003;18(4):696-704

95. Moshaverinia A, Chen $\mathrm{C}, \mathrm{Xu} \mathrm{X}$, et al. Bone regeneration potential of stem cells derived from periodontal ligament or gingival tissue sources encapsulated in RGD-modified alginate scaffold. Tissue Eng Part A. 2014;20(3-4):611-621.

96. Menicanin D, Mrozik KM, Wada N, et al. Periodontal-ligament-derived stem cells exhibit the capacity for long-term survival, self-renewal, and regeneration of multiple tissue types in vivo. Stem Cells Dev. 2014;23(9):1001-1011.

97. Zheng Y, Liu Y, Zhang CM, et al. Stem cells from deciduous tooth repair mandibular defect in swine. J Dent Res. 2009;88(3):249-254.

98. Kim SH, Kim KH, Seo BM, et al. Alveolar bone regeneration by transplantation of periodontal ligament stem cells and bone marrow stem cells in a canine peri-implant defect model: a pilot study. J Periodontol. 2009;80(11):1815-1823.

99. d'Aquino R, De Rosa A, Lanza V, et al. Human mandible bone defect repair by the grafting of dental pulp stem/progenitor cells and collagen sponge biocomplexes. Eur Cell Mater. 2009;18:75-83.

100. Giuliani A, Manescu A, Langer M, et al. Three years after transplants in human mandibles, histological and in-line holotomography revealed that stem cells regenerated a compact rather than a spongy bone: biological and clinical implications. Stem Cells Transl Med. 2013;2(4):316-324.

101. Annibali S, Cicconetti A, Cristalli MP, et al. A comparative morphometric analysis of biodegradable scaffolds as carriers for dental pulp and periosteal stem cells in a model of bone regeneration. J Craniofac Surg. 2013;24(3):866-871.

102. Morad G, Kheiri L, Khojasteh A. Dental pulp stem cells for in vivo bone regeneration: a systematic review of literature. Arch Oral Biol. 2013;58(12):1818-1827.

103. Zhang W, Walboomers XF, van Osch GJ, van den Dolder J, Jansen JA. Hard tissue formation in a porous HA/TCP ceramic scaffold loaded with stromal cells derived from dental pulp and bone marrow. Tissue Eng Part A. 2008;14(2):285-294.

104. Yang X, Han G, Pang X, Fan M. Chitosan/collagen scaffold containing bone morphogenetic protein-7 DNA supports dental pulp stem cell differentiation in vitro and in vivo. J Biomed Mater Res A. 2012

105. Zhang W, Walboomers XF, van Kuppevelt TH, Daamen WF, Bian Z, Jansen JA. The performance of human dental pulp stem cells on different three-dimensional scaffold materials. Biomaterials. 2006;27(33): 5658-5668.

106. Yu J, He H, Tang C, et al. Differentiation potential of STRO-1+ dental pulp stem cells changes during cell passaging. BMC Cell Biol. 2010;11:32. 
107. Karp JM, Ferreira LS, Khademhosseini A, Kwon AH, Yeh J, Langer RS. Cultivation of human embryonic stem cells without the embryoid body step enhances osteogenesis in vitro. Stem Cells. 2006;24(4):835-843.

108. Tong W, Brown SE, Krebsbach PH. Human embryonic stem cells undergo osteogenic differentiation in human bone marrow stromal cell microenvironments. J Stem Cells. 2007;2(3):139-147.

109. Hu J, Smith LA, Feng K, Liu X, Sun H, Ma PX. Response of human embryonic stem cell-derived mesenchymal stem cells to osteogenic factors and architectures of materials during in vitro osteogenesis. Tissue Eng Part A. 2010;16(11):3507-3514.

110. Hall BK, Miyake T. Divide, accumulate, differentiate: cell condensation in skeletal development revisited. Int J Dev Biol. 1995;39(6):881-893.

111. MacDonald ME, Hall BK. Altered timing of the extracellular-matrixmediated epithelial-mesenchymal interaction that initiates mandibular skeletogenesis in three inbred strains of mice: development, heterochrony, and evolutionary change in morphology. J Exp Zool. 2001;291(3):258-273.

112. Aszódi A, Bateman JF, Gustafsson E, Boot-Handford R, Fässler R. Mammalian skeletogenesis and extracellular matrix: what can we learn from knockout mice? Cell Struct Funct. 2000;25(2):73-84.

113. Ma PX. Biomimetic materials for tissue engineering. Adv Drug Deliv Rev. 2008;60(2):184-198.

114. Grinnemo KH, Kumagai-Braesch M, Månsson-Broberg A, et al. Human embryonic stem cells are immunogenic in allogeneic and xenogeneic settings. Reprod Biomed Online. 2006;13(5):712-724.

115. Aldahmash A, Atteya M, Elsafadi M, et al. Teratoma formation in immunocompetent mice after syngeneic and allogeneic implantation of germline capable mouse embryonic stem cells. Asian Pac J Cancer Prev. 2013;14(10):5705-5711.

116. Worringer KA, Rand TA, Hayashi Y, et al. The let-7/LIN-41 pathway regulates reprogramming to human induced pluripotent stem cells by controlling expression of prodifferentiation genes. Cell Stem Cell. 2014;14(1):40-52.

117. Walia B, Satija N, Tripathi RP, Gangenahalli GU. Induced pluripotent stem cells: fundamentals and applications of the reprogramming process and its ramifications on regenerative medicine. Stem Cell Rev. 2012;8(1):100-115.
118. Takahashi K, Yamanaka S. Induction of pluripotent stem cells from mouse embryonic and adult fibroblast cultures by defined factors. Cell. 2006;126(4):663-676.

119. Yu J, Vodyanik MA, Smuga-Otto K, et al. Induced pluripotent stem cell lines derived from human somatic cells. Science. 2007;318(5858):1917-1920.

120. Ohradanova A, Gradin K, Barathova M, et al. Hypoxia upregulates expression of human endosialin gene via hypoxia-inducible factor 2 . Br J Cancer. 2008;99(8):1348-1356.

121. Kao CL, Tai LK, Chiou SH, et al. Resveratrol promotes osteogenic differentiation and protects against dexamethasone damage in murine induced pluripotent stem cells. Stem Cells and Dev. 2010;19(2):247-258

122. Uto S, Nishizawa S, Takasawa $\mathrm{Y}$, et al. Bone and cartilage repair by transplantation of induced pluripotent stem cells in murine joint defect model. Biomed Res. 2013;34(6):281-288.

123. Jin GZ, Kim TH, Kim JH, et al. Bone tissue engineering of induced pluripotent stem cells cultured with macrochanneled polymer scaffold. J Biomed Mater Res A. 2013;101(5):1283-1291.

124. Levi B, Hyun JS, Montoro, et al. In vivo directed differentiation of pluripotent stem cells for skeletal regeneration. Proc Natl Acad Sci USA. 2012;109(50):20379-20384.

125. Kumazaki T, Kurata S, Matsuo T, Mitsui Y, Takahashi T. Establishment of human induced pluripotent stem cell lines from normal fibroblast TIG-1. Hum Cell. 2011;24(2):96-103.

126. Brambrink T, Foreman R, Welstead GG, et al. Sequential expression of pluripotency markers during direct reprogramming of mouse somatic cells. Cell Stem Cell. 2008;2(2):151-159.

127. Stadtfeld M, Maherali N, Breault DT, Hochedlinger K. Defining molecular cornerstones during fibroblast to iPS cell reprogramming in mouse. Cell Stem Cell. 2008;2(3):230-240.

128. Romagnoli C, Brandi ML. Adipose mesenchymal stem cells in the field of bone tissue engineering. World J Stem Cells. 2014;6(2): 144-152.

129. Fang D, Nguyen TK, Leishear K, et al. A tumorigenic subpopulation with stem cell properties in melanomas. Cancer Res. 2005; 65(20):9328-9337.
Stem Cells and Cloning: Advances and Applications

\section{Publish your work in this journal}

Stem Cells and Cloning: Advances and Applications is an international, peer-reviewed, open access journal. Areas of interest in stem cell research include: Embryonic stem cells; Adult stem cells; Blastocysts; Cordblood stem cells; Stem cell transformation and culture; Therapeutic cloning; Umbilical cord blood and bone marrow cells; Laboratory,

\section{Dovepress}

animal and human therapeutic studies; Philosophical and ethical issues related to stem cell research. This journal is indexed on CAS. The manuscript management system is completely online and includes a quick and fair peer-review system. Visit http://www.dovepress.com/ testimonials.php to read real quotes from published authors. 